\title{
Влияние структурно-морфологических характеристик на сенсорные свойства пленок $\mathrm{Cd}_{x} \mathrm{~Pb}_{1-x} \mathrm{~S}$
}

\author{
(С) Л.Н. Маскаева ${ }^{1,2}$, И.В. Ваганова ${ }^{1,2}$, В.Ф. Марков ${ }^{1,2}$, А.Е. Бездетнова ${ }^{1,2}$, А.Д. Селянина ${ }^{1,2}$, \\ В.И. Воронин ${ }^{3}$, И.О. Селянин ${ }^{1,4}$
}

\author{
${ }^{1}$ Уральский федеральный университет им. первого Президента России Б.Н. Ельцина, \\ 620002 Екатеринбург, Россия \\ ${ }^{2}$ Уральский институт ГПС МЧС России, \\ 620062 Екатеринбург, Россия \\ ${ }^{3}$ Институт фризики металлов им. М.Н. Михеева Уральского отделения Российской академии наук, \\ 620108 Екатеринбург, Россия \\ ${ }^{4}$ Институт химии твердого тела Уральского отделения Российской академии наук, \\ 620990 Екатеринбург, Россия \\ E-mail: larisamaskaeva@yandex.ru
}

Поступила в Редакцию 31 июля 2021 г.

В окончательной редакции 5 августа 2021 г.

Принята к публикации 5 августа 2021 г.

\begin{abstract}
Химическим осаждением на ситалловую подложку при варьировании в реакционной смеси концентрации соли ацетата кадмия $\mathrm{Cd}\left(\mathrm{CH}_{3} \mathrm{COO}\right)_{2}$ в пределах 0.01-0.10 моль/л получены поликристаллические пленки пересыщенных твердых растворов замещения $\mathrm{Cd}_{x} \mathrm{~Pb}_{1-x} \mathrm{~S}(0.021 \leq x \leq 0.090)$ с кубической структурой $B 1$ (пр. гр. $F m \overline{3} m$ ) толщиной от $\sim 0.4$ до $\sim 1.0$ мкм. Установлена корреляция между структурноморфологическими и функциональными свойствами тонкопленочных слоев $\mathrm{Cd}_{x} \mathrm{~Pb}_{1-x} \mathrm{~S}$. Экстремальный характер зависимости вольтовой чувствительности от концентрации соли кадмия в реакционной ванне связан с немонотонным вхождением кадмия в кристаллическую решетку $\mathrm{PbS}$. Показано, что максимальным фототоком обладают тонкопленочные слои $\mathrm{Cd}_{x} \mathrm{~Pb}_{1-x} \mathrm{~S}$, сформированные из кристаллитов, имеющих выраженную кристаллографическую огранку. Обнаружена поверхностная чувствительность пленок $\mathrm{Cd}_{x} \mathrm{~Pb}_{1-x} \mathrm{~S}$ к присутствию $\sim 0.02 \mathrm{M} / \mathrm{M}^{3} \mathrm{NO}_{2}$ в воздушной среде, что значительно ниже принятых предельно допустимых концентраций.
\end{abstract}

Ключевые слова: химическое осаждение, морфология пленок, структурные свойства, твердый раствор $\mathrm{Cd}_{x} \mathrm{~Pb}_{1-x} \mathrm{~S}$, фоточувствительность, сенсорные свойства.

DOI: $10.21883 /$ FTP.2021.12.51704.9726

\section{1. Введение}

Длительное время не ослабевает интерес к твердым растворам на основе полупроводниковых соединений $\mathrm{A}^{\mathrm{II}}-\mathrm{B}^{\mathrm{VI}}$ и $\mathrm{A}^{\mathrm{IV}}-\mathrm{B}^{\mathrm{VI}}$, расширяющих возможность модификации структурных, полупроводниковых, функциональных свойств индивидуальных халькогенидов металлов и обеспечивающих их вариабельное изменение в довольно широких пределах. Тонкопленочный сульфид свинца $\mathrm{PbS}$ в поликристаллическом состоянии - это узкозонный полупроводник с кубической (пр. гр. $F m \overline{3} m$ ) структурой и шириной запрещенной зоны 0.41 эВ при $300 \mathrm{~K}[1]$. Благодаря фоточувствительности в широком диапазоне спектра (0.4-3.0 мкм) сульфид свинца применяется в оптоэлектронных и сенсорных устройствах [2-5].

Сульфид кадмия $\mathrm{CdS}$ со структурой типа вюрцита $B 4$ (пр.гр. $\left.P 6_{3} m c\right)$ или сфалерита $B 3$ (пр.гр. $F \overline{4} 3 m$ ) является широкозонным полупроводником с шириной запрещенной зоны 2.42 эВ [6]. Сульфид кадмия также широко используется в качестве буферного слоя в фотовольтаических, оптоэлектронных и фотокаталитических устройствах.

Наиболее востребованными являются пленки твердых растворов $\mathrm{Cd}_{x} \mathrm{~Pb}_{1-x} \mathrm{~S}$ с вариабельной шириной запре- щенной зоны в пределах от 0.4 до 2.42 эВ, позволяющие охватить все спектральные свойства этих соединений [7-13]. Регулирование химического состава дает возможность контролируемым образом конструировать перспективные материалы на их основе. Следовательно, создание твердых растворов $\mathrm{Cd}_{x} \mathrm{~Pb}_{1-x} \mathrm{~S}$ в тонкопленочном состоянии простыми и дешевыми методами сегодня является актуальной задачей. Наиболее привлекательным является метод химического осаждения из водных сред (CBD) [4,8,11,13-19]. Этот метод отличается своей аппаратурной простотой и низкотемпературными условиями проведения. Он позволяет изменять условия синтеза (состав и концентрации химических реагентов, температуру и длительность процесса, природу подложки для осаждения и прочее) и дает возможность подобрать условия для получения пленок $\mathrm{Cd}_{x} \mathrm{~Pb}_{1-x} \mathrm{~S}$ c оптимальными свойствами для конкретных устройств.

Анализ научной литературы показывает противоречивость и фрагментарный характер полученных результатов о составе и свойствах тонкопленочных твердых растворов $\mathrm{Cd}_{x} \mathrm{~Pb}_{1-x} \mathrm{~S}$, а также не всегда их верную интерпретацию. Это связано со сложностью и многофакторностью процесса химического осаждения обсуждаемых пленок, не позволяющих решить одну из 
фундаментальных задач полупроводникового материаловедения, в частности, найти связь между структурными и функциональными свойствами.

С учетом отмеченного, целью настоящего исследования является комплексное изучение морфологии поверхности, кристаллической структуры и сенсорных свойств пленок твердых растворов $\mathrm{Cd}_{x} \mathrm{~Pb}_{1-x} \mathrm{~S}$, что позволит выявить природу происходящих в них изменений и найти взаимосвязи в ряду „синтез-состав-структурасвойство“.

\section{2. Методика эксперимента}

Объектом исследования являлись тонкопленочные слои в системе $\mathrm{CdS}-\mathrm{PbS}$, которые синтезировали методом химического осаждения из аммиачно-цитратной реакционной ванны, которые содержали 0.04 моль/л ацетата свинца $\mathrm{Pb}\left(\mathrm{CH}_{3} \mathrm{COO}\right)_{2}, 0.3$ моль/л цитрата натрия $\mathrm{Na}_{3} \mathrm{C}_{6} \mathrm{H}_{5} \mathrm{O}_{7}, 4.5$ моль/л гидроксида аммония $\mathrm{NH}_{4} \mathrm{OH}$ и 0.58 моль/л, тиомочевины $\mathrm{N}_{2} \mathrm{H}_{4} \mathrm{CS}$ (источник сульфидионов). Концентрацию ацетата кадмия $\mathrm{Cd}\left(\mathrm{CH}_{3} \mathrm{COO}\right)_{2}$ варьировали в интервале 0.01-0.10 моль/л. Осаждение обсуждаемых пленок проводили в течение 120 мин при температуре $353 \mathrm{~K}$ в герметичных реакторах из молибденового стекла, в которые погружали обезжиренные подложки из ситалла марки СТ-50-1, закрепленные во фторопластовые приспособления. Реакторы устанавливали в термостат марки „ТС-ТБ-10“ с точностью поддержания температуры $\pm 0.1 \mathrm{~K}$. После синтеза пленки промывали дистиллированной водой и сушили на воздухе.

Толщину полученных пленок определяли с помощью интерференционного микроскопа (микроинтерферометра Линника) МИИ-4М, погрешность измерения которого составляла $20 \%$.

Микроструктуру и элементный анализ пленок твердых растворов $\mathrm{Cd}_{x} \mathrm{~Pb}_{1-x} \mathrm{~S}$ изучали методом растровой электронной микроскопии высокого разрешения на микроскопе MIRA 3 LMU при ускоряющем напряжении электронного пучка 10 кВ, а также на растровом электронном микроскопе JEOL JSM-5900 LV с энергодисперсионным рентгеновским анализатором EDS Inca Energy 250.

Рентгеноструктурные исследования образцов проводили на двух дифрактометрах: лабораторном прибоpe PANalytical Empyrean Series 2 в $\mathrm{Cu} K_{\alpha}$-излучении в геометрии параллельного пучка с позиционночувствительным детектором PIXel3D, обеспечивающим разрешение по шкале $2 \theta$ не менее 0.0016 и стандартном промышленном дифрактометре Дрон-4. Измерения проводили в геометрии традиционной дифракции БрэггаБрентано в интервале $2 \theta$ от 20 до $80^{\circ}$. Определение состава и структурных параметров пленок $\mathrm{Cd}_{x} \mathrm{~Pb}_{1-x} \mathrm{~S}$ проводили методом полнопрофильного анализа Ритвелда $[20,21]$ с использованием компьютерной программы FullProf [22]. Для определения размера частиц, формирующих пленки $\mathrm{Cd}_{x} \mathrm{~Pb}_{1-x} \mathrm{~S}$, и возникающих в них деформаций использовали уравнение Уильямсона-Холла (conventional Williamson-Hall plot) [23]:

$$
\beta \cdot \cos \theta=0.9 \lambda / D+4 \varepsilon \cdot \sin \theta,
$$

где $D-$ средний размер областей когерентного рассеяния, принимаемого за средний размер частиц, $\beta-$ полуширина рефлекса в радианах, $\lambda$ - длина волны используемого рентгеновского излучения, $\varepsilon=\Delta d / d-$ деформация, $d$ - межплоскостное расстояние.

Тип проводимости пленок определяли по знаку термоэдс при создании градиента температуры в области зондовых контактов.

Фотоэлектрические характеристики (темновое сопротивление $R_{d}$, вольтовую чувствительность $U_{s}$ ) пленок $\mathrm{CdPbS}$ измеряли на установке К.54.410 с источником излучения АЧТ $573 \mathrm{~K}$ при частоте модуляции 800 Гц и облученности $1 \cdot 10^{-4} \mathrm{BT} / \mathrm{cm}^{2}$.

Вольт-амперные характеристики синтезированных пленок регистрировали при температуре $298 \mathrm{~K}$ в диапазоне приложенного напряжения от -10 до $10 \mathrm{~B}$ с шагом $100 \mathrm{MB}$ двухзондовым методом как в темноте, так и при освещенности $100 \mathrm{MBT} / \mathrm{cm}^{2}$ пучком света от симулятора солнечного излучения Zolix GLORIA-X500A, оборудованного лампой Osram XBO 500W/H OFR. Beличину силы тока определяли источником-измерителем Keithley 2450.

На основе пленок твердых растворов $\mathrm{Cd}_{x} \mathrm{~Pb}_{1-x} \mathrm{~S}$ изготавливали сенсорные элементы с чувствительной площадкой $5 \times 5$ мм. В качестве электрических контактов на сенсорных элементах использовали электрохимически нанесенный никель. Омическое сопротивление пленок измеряли с помощью комбинированного цифрового прибора Щ 301-1. Сенсорные свойства пленок по отношению к диоксиду азота исследовали в специально разработанной герметичной ячейке, в которой с помощью прижимных контактов устанавливали сенсорный элемент и подавали газовоздушную смесь. При выполнении работы использовали газовые смеси с исходными концентрациями диоксида азота в воздушной среде 0.08 , $8.0,40$ и $200 \mathrm{мг} / \mathrm{M}^{3}$. Температура газовоздушных смесей составляла $295 \mathrm{~K}$, давление было атмосферным.

\section{3. Результаты и обсуждение}

\section{1. Исследование морфологии}

Зависимость толщины синтезированных слоев в системе $\mathrm{PbS}-\mathrm{CdS}$ от содержания ацетата кадмия в реакционной смеси при фиксированных концентрациях остальных компонентов системы имеет экстремальный характер. Повышение содержания $\mathrm{Cd}\left(\mathrm{CH}_{3} \mathrm{COO}\right)_{2}$ от 0.01 до 0.08 моль/л приводит к монотонному росту толщины полупроводникового слоя от $\sim 0.5$ до $\sim 1.0$ мкм. При концентрации ацетата кадмия в реакторе 0.1 моль/л происходит резкое снижение толщины слоя $\mathrm{Cd}_{x} \mathrm{~Pb}_{1-x} \mathrm{~S}$ до $\sim 0.6$ мкм, что можно объяснить, исходя из кинетических данных, перераспределением сульфидов свинца и кадмия в осадок. 

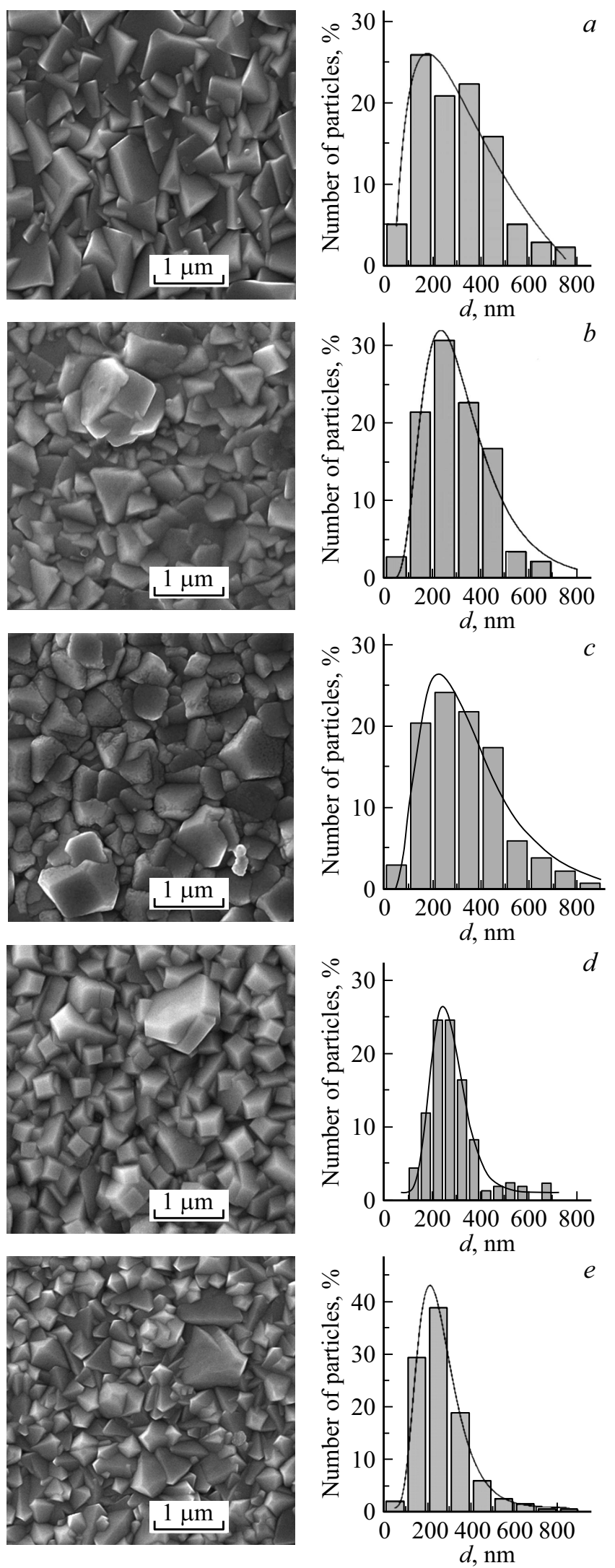

Рис. 1. Микрофотографии пленок $\mathrm{CdPbS}$, осажденных на подложки из ситалла из реакционной смеси, содержащей $\mathrm{Cd}\left(\mathrm{CH}_{3} \mathrm{COO}\right)_{2}$, моль/л: $0.01(a), 0.02(b), 0.04(c), 0.08(d)$, $0.10(e)$, и полуширина аппроксимирующих кривых Гаусса, характеризующих разброс зерен по размерам.
Важнейшими характеристиками тонкопленочного трехкомпонентного соединения $\mathrm{CdPbS}$ на диэлектрических подложках являются размер и форма зерен, определяющих их как структурные, так и функциональные свойства. Электронно-микроскопические изображения пленок $\mathrm{Cd}_{x} \mathrm{~Pb}_{1-x} \mathrm{~S}$ при варьировании концентрации ацетата кадмия от 0.01 до 0.10 моль/л в реакционной смеси и разброс зерен по размерам, представленный в виде полуширины аппроксимирующей кривой Гаусса, приведены на рис. 1. Во всем интервале концентраций соли кадмия в растворе происходит формирование на подложке из ситалла хорошо ограненных кристаллитов в форме октаэдров, тетраэдров или же усеченных полиэдров типа кубооктаэдров различного размера и их ориентации относительно плоскости подложки. Исключение представляет пленка, полученная при концентрации в реакторе 0.04 моль/л $\mathrm{Cd}\left(\mathrm{CH}_{3} \mathrm{COO}\right)_{2}$, у которой кардинально изменяется микроструктура, за счет превращения кристаллитов в плоские зерна с округленными гранями и неровными краями. Так как форма зерен не является правильной, а изображение плоское, то была проведена оценка так называемого статистического диаметра, за который была принята длина хорды, делящая площадь проекции зерна на две примерно равные части (диаметр Мартина).

Для анализа морфологии пленок $\mathrm{CdPbS}$ была использована гауссова кривая распределения среднего размера зерна $\langle R\rangle$ и разброс зерен по размерам, определяемый по полуширине аппроксимирующей кривой Гаусса $\Delta R$ в зависимости от концентрации ацетата кадмия в реакторе (рис. 2). С увеличением концентрации соли кадмия от 0.01 до 0.04 моль/л средний размер зерен, формирующих пленку $\mathrm{CdPbS}$, увеличивается от 270 до $\sim 300$ нм. Дальнейшее повышение содержания соли кадмия приводит к уменьшению их размера до 260 и 230 нм при 0.08 и 0.1 моль/л соответственно.

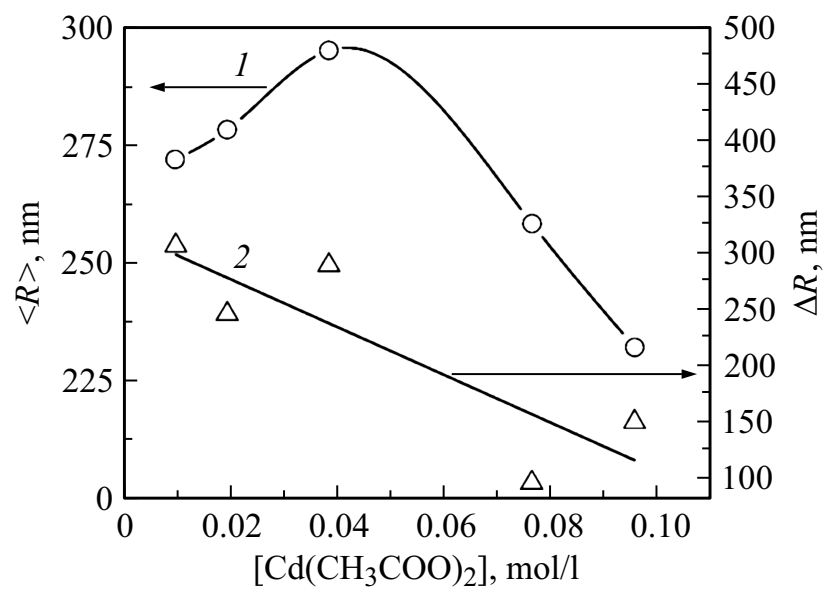

Рис. 2. Зависимости среднего размера зерен (1), формирующих пленку $\mathrm{CdPbS}$ на ситалле при химическом осаждении из реакционной ванны с различным содержанием $\mathrm{Cd}\left(\mathrm{CH}_{3} \mathrm{COO}\right)_{2}$ и полуширины аппроксимирующих кривых Гаусса, характеризующих разброс зерен по размерам (2). 
Иное поведение демонстрирует изменение размера зерен, определяемое по полуширине аппроксимирующей кривой Гаусса $(\Delta R)$. Наблюдается монотонное уменьшение размера и повышение однородности зерен с ростом концентрации $\mathrm{Cd}\left(\mathrm{CH}_{3} \mathrm{COO}\right)_{2}$ в реакционной ванне (рис. 2). Таким образом, во всем интервале исследованных концентраций соли кадмия в реакторе выявленные морфологические особенности кристаллитов в пленках на ситалле сохраняются, но изменяется их размер и среднее отклонение от него.

Анализ полученных результатов позволяет высказать предположение о том, что выявленные особенности морфологии обсуждаемых пленок определяются концентрацией ацетата кадмия в реакционной ванне, условиями зародышеобразования, а также роста слоев на подложке. Используемые в работе подложки из ситалла СТ-50-1, представляющего собой стеклокерамический полукристаллический материал, содержащий „каталитические добавки“, стимулируют возникновение большого количества центров кристаллизации и создают условия для образования поликристаллической структуры. Таким образом, выполненные электронно-микроскопические исследования продемонстрировали значительное влияние концентрации соли кадмия на микроструктуру осаждаемых пленок $\mathrm{CdPbS}$.

\section{2. Кристаллическая структура}

Ключевым параметром, определяющим фото- и сенсорные свойства синтезированных пленок в системе $\mathrm{CdS}-\mathrm{PbS}$, наряду с морфологией является их структурное состояние, т.е. тип кристаллической решетки, размер зерен, дефектность и внутренние микронапряжения. Исследователи в основном ограничиваются определением размеров кристаллитов из уширения отдельных линий рентгеновского рассеяния, игнорируя возможный вклад от остальных структурных параметров. В настоящей работе нами изучен комплекс структурного состояния пленок $\mathrm{CdPbS}$, используя всю область углов рассеяния (профиль рентгенограммы), что повысило точность и надежность выводов. Для этого было использовано моделирование с помощью компьютерного комплекса FullProf, в котором реализован метод полнопрофильного анализа Ритвелда.

На рентгенограммах синтезированных пленок $\mathrm{CdPbS}$, приведенных на рис. 3, присутствует набор дифракционных отражений, характерный для кубической гранецентрированной решетки типа $\mathrm{NaCl}(B 1$, пр.гр. $F m \overline{3} m)$. Bce они имеют хорошо выраженную форму кривых, близкую гауссовой или лоренцевой, и достаточно небольшую ширину рефлексов, т. е. можно констатировать, что практически все изучаемые трехкомпонентные слои являются поликристаллическими.

Убедительным доказательством образования твердых растворов замещения $\mathrm{Cd}_{x} \mathrm{~Pb}_{1-x} \mathrm{~S}$ служит смещение всех дифракционных отражений в область дальних углов $2 \theta$ (рис. 3, фрагмент рентгенограмм с рефлексом (311) В1),

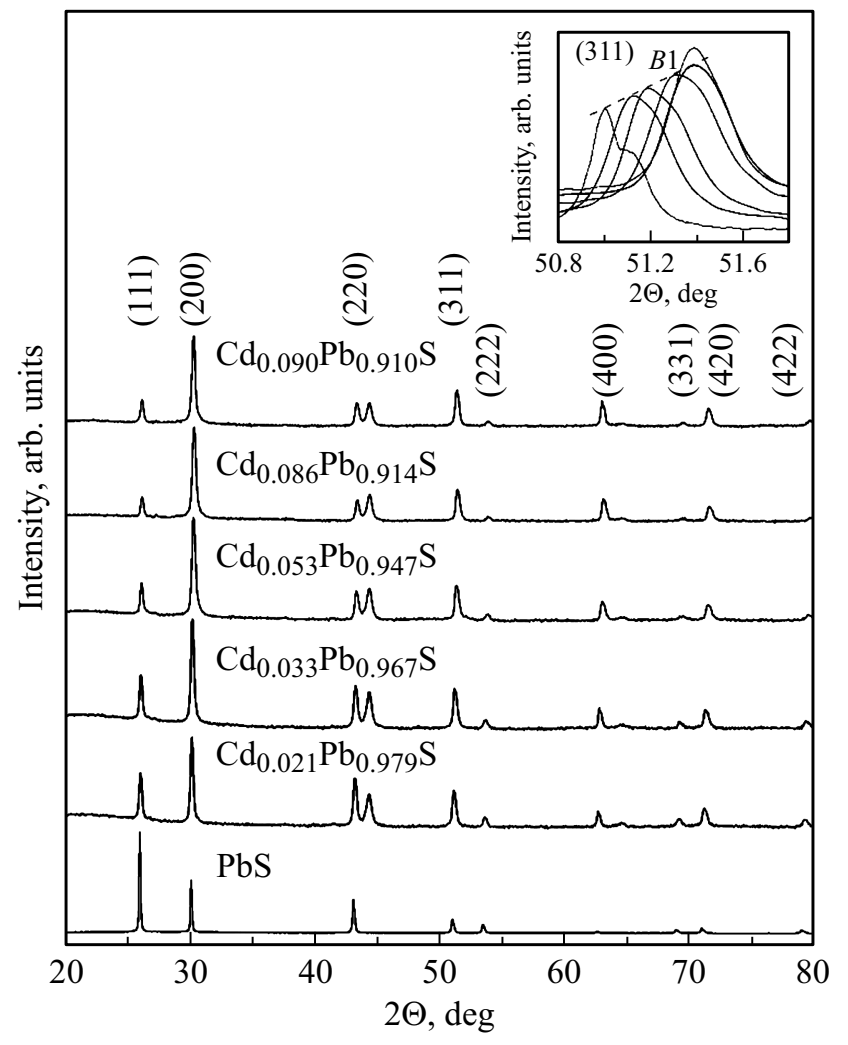

Рис. 3. Экспериментальные рентгенограммы пленок твердых растворов $\mathrm{Cd}_{0.021} \mathrm{~Pb}_{0.979} \mathrm{~S}, \mathrm{Cd}_{0.033} \mathrm{~Pb}_{0.967} \mathrm{~S}, \mathrm{Cd}_{0.053} \mathrm{~Pb}_{0.947} \mathrm{~S}$, $\mathrm{Cd}_{0.086} \mathrm{~Pb}_{0.914} \mathrm{~S}, \mathrm{Cd}_{0.090} \mathrm{~Pb}_{0.910} \mathrm{~S}$, полученных химическим осаждением на ситалловой подложке из реакционной ванны, содержащей $\mathrm{Cd}\left(\mathrm{CH}_{3} \mathrm{COO}\right)_{2}$, моль/л: 0.01, 0.02, 0.04, 0.08, 0.1. На вставке показано смещение отражения (311) $)_{B 1}$ твердых растворов $\mathrm{Cd}_{x} \mathrm{~Pb}_{1-x} \mathrm{~S}$ в область дальних углов $2 \theta$ при замещении атомов $\mathrm{Pb}$ атомами $\mathrm{Cd}$.

т.е. уменьшение периода $a_{B 1}$. Наблюдаемое уменьшение $a_{B 1}$ от $0.59242(1)$ до $0.58918(1) \mathrm{HM}$ (табл. 1) обусловлено замещением ионов свинца $\mathrm{Pb}^{2+}(0.120 \mathrm{Hм})$ ионами кадмия $\mathrm{Cd}^{2+}(0.097 \mathrm{Hм})$ в решетке $\mathrm{PbS}$. Количественный анализ рентгенограмм позволил также оценить величину $x$ в твердых растворах $\mathrm{Cd}_{x} \mathrm{~Pb}_{1-x} \mathrm{~S}$, т. е. относительное содержание кадмия в металлической подрешетке. Оценку относительного содержания $\mathrm{Cd}$ в твердом растворе замещения проводили по правилу Вегарда как $x=\left(a_{\mathrm{PbS}}-a_{s s}\right) /\left(a_{\mathrm{PbS}}-a_{\mathrm{CdS}}\right)$, где $a_{\mathrm{PbS}}, a_{\mathrm{CdS}}$, $a_{s s}$ - параметры кристаллических решеток сульфида свинца, сульфида кадмия и твердого раствора замещения $\mathrm{Cd}_{x} \mathrm{~Pb}_{1-x} \mathrm{~S}$. Для расчета $x$ использовали значение периода кристаллической решетки пленки $\mathrm{PbS}$ $\left(a_{\mathrm{PbS}}=0.59332 \mathrm{HM}\right)$, полученной из реакционной ванны исключением соли кадмия. Поскольку твердые растворы замещения $\mathrm{Cd}_{x} \mathrm{~Pb}_{1-x} \mathrm{~S}$ сохраняют кубическую структуpy $\mathrm{PbS}$, можно принять, что решетка сульфида кадмия в области ограниченной растворимости искажается до кубической. Поэтому период модельной кубической элементарной ячейки $\mathrm{CdS}$, теоретически определенный нами при использовании эмпирического размера кати- 


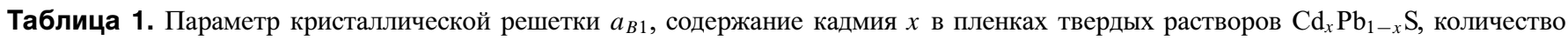
зерен с преимущественной ориентацией $(200)$, параллельной плоскости подложки $T_{(200)}$, размер областей когерентного рассеяния ОКР $(D)$ и среднее значение микродеформаций $\Delta d / d$

\begin{tabular}{c|c|c|c|c|c}
\hline $\mathrm{Cd}\left(\mathrm{CH}_{3} \mathrm{COO}\right)_{2}$, моль/л & 0.01 & 0.02 & 0.04 & 0.08 & 0.10 \\
\hline$a_{B 1}, \mathrm{HM}$ & $0.59242(1)$ & $0.59187(1)$ & $0.59094(1)$ & $0.58951(1)$ & $0.58918(1)$ \\
$x \mathrm{Cd}_{x} \mathrm{~Pb}_{1-x} \mathrm{~S}$ & 0.021 & 0.033 & 0.053 & 0.086 & 0.090 \\
$T(200), \%$ & 6 & 26.2 & 32.3 & 34.9 & 24.2 \\
$D$, нм & 227 & 232 & 302 & 300 & 324 \\
$\Delta d / d \cdot 10^{4}$ & 8.84 & 9.38 & 14.9 & 18.3 & 18.9
\end{tabular}

онов $\mathrm{Cd}^{2+}$ в 6-кратном окружении в решетке $\mathrm{NaCl}$, равен $a_{\mathrm{CdS}}=0.546$ нм. Рассчитанное содержание кадмия в решетке $\mathrm{PbS}$, приведенное в табл. 1 , свидетельствует о формировании сильно пересыщенных твердых растворов замещения $\mathrm{Cd}_{x} \mathrm{~Pb}_{1-x} \mathrm{~S}(0 \leq x \leq 0.09)$. Учитывая, что синтез пленок проводился при $353 \mathrm{~K}$, достигнутый уровень пересыщения по $\mathrm{CdS}$ более чем на 4 порядка превышает данные равновесной фазовой диаграммы системы PbS-CdS [24].

Еще одной особенностью полученных рентгенограмм, свидетельствующих об образовании твердых растворов замещения в системе $\mathrm{CdS}-\mathrm{PbS}$, является постепенное изменение соотношения интенсивностей отражений $(111)_{B 1}$ и $(200)_{B 1}$ при повышении концентрации $\mathrm{Cd}\left(\mathrm{CH}_{3} \mathrm{COO}\right)_{2}$ в реакторе (рис. 3). Соотношение интенсивностей рефлексов $(111)_{B 1}$ и $(200)_{B 1}$ показывает, что в пленках реализовалась частичная ориентировка зерен преимущественно с кристаллографической плоскостью (200).

Разделение размерного и деформационного вкладов в уширение отражений для оценки среднего размера зерен и микродеформаций выполнено с использовани-

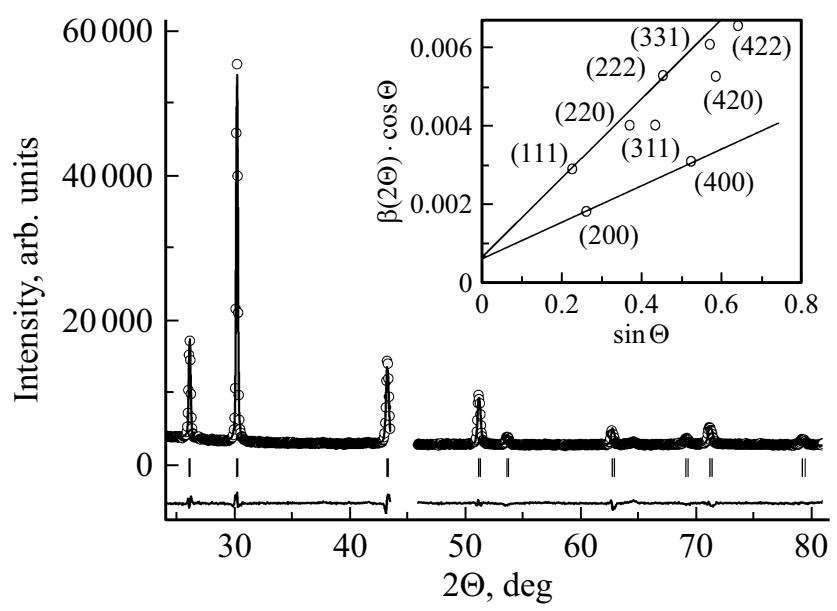

Рис. 4. Экспериментальная (точки) и расчетная (огибающая линия) рентгенограммы пленки твердого раствора $\mathrm{Cd}_{x} \mathrm{~Pb}_{1-x} \mathrm{~S}$, осажденной из реакционной ванны, содержащей 0.01 моль/л $\mathrm{Cd}\left(\mathrm{CH}_{3} \mathrm{COO}\right)_{2}$. Нижняя линия - разница между расчетными и экспериментальными картинами рентгеноструктурного анализа. Штрихами обозначены угловые положения пиков фазы $B 1$. На вставке показана зависимость $\beta \cdot(2 \theta) \cdot \cos \theta$ от $\sin \theta$.
Таблица 2. Результаты энергодисперсионного элементного микроанализа тонкопленочных соединений $\mathrm{CdPbS}$ в зависимости от содержания ацетата кадмия в реакционной смеси

\begin{tabular}{c|r|c|c|c|c}
\hline Элемент, ат\% & \multicolumn{1}{|c|}{0.01} & 0.02 & 0.04 & 0.08 & 0.10 \\
\hline $\mathrm{Cd}$ & 9.10 & 13.04 & 14.83 & 4.60 & 21.20 \\
$\mathrm{~Pb}$ & 41.06 & 37.06 & 35.17 & 44.65 & 28.98 \\
$\mathrm{~S}$ & 49.83 & 49.90 & 50.01 & 50.75 & 49.82
\end{tabular}

ем традиционного подхода на примере рентгенограммы пленки твердого раствора $\mathrm{Cd}_{0.021} \mathrm{~Pb}_{0.979} \mathrm{~S}$, полученной из реакционной ванны с содержанием 0.01 моль/л $\mathrm{Cd}\left(\mathrm{CH}_{3} \mathrm{COO}\right)_{2}$ (рис. 4). На вставке показана зависимость физического уширения от угла в виде $\beta \cdot(2 \theta) \cdot \cos \theta$ от $\sin \theta$. Наклон этих зависимостей указывает на наличие деформаций в частицах, а отсекаемый отрезок на оси ординат $(\sin \theta=0)$ дает их размер. Подобные операции применены к анализу всех дифракционных спектров.

Значения среднего размера зерен, формирующих пленки твердых растворов $\mathrm{Cd}_{x} \mathrm{~Pb}_{1-x} \mathrm{~S}$, и усредненные по объему микродеформации от концентрации ацетата кадмия в реакционной ванне приведены в табл. 1.

Размер областей когерентного рассеяния $D$ (в первом приближении средний размер зерна) увеличивается от 227 до 324 нм с одновременным ростом микродеформаций в объеме пленки в $\sim 2$ раза с повышением концентрации соли кадмия от 0.01 до 0.1 моль/л.

Для установления элементного состава синтезированных пленок был проведен локальный энергодисперсионный элементный микроанализ (EDX) по всей площади поверхности слоев не менее чем в 10 точках. Усредненные результаты элементного анализа на содержание свинца, кадмия и серы, приведенные в табл. 2, позволяют заключить, что содержание соли кадмия в составе реакционной смеси оказывает существенное влияние на состав пленок. В интервале концентраций соли $\mathrm{Cd}\left(\mathrm{CH}_{3} \mathrm{COO}\right)_{2}$ от 0.01 до 0.04 моль/л в реакторе наблюдается увеличение доли кадмия в составе пленки $\mathrm{CdPbS}$ от 9.1 до $14.83 \mathrm{aT} \%$. Дальнейшее повышение концентрации соли кадмия в реакторе до 0.08 моль/л приводит к снижению содержания этого металла до 4.60 aт\%, а при 0.1 моль/л к значительному его повышению до 21.20 ат\%. 
При этом сумма металлов $(\mathrm{Cd}+\mathrm{Pb})$ в пленках преобладает над содержанием халькогена до концентраций соли кадмия в реакторе, равных 0.01 и 0.02 моль/л, когда слой формируют хорошо ограненные кристаллиты, покрывающие поверхность подложки (рис. $1, a, b)$. Состав пленки, полученной при 0.04 моль/л $\mathrm{Cd}\left(\mathrm{CH}_{3} \mathrm{COO}\right)_{2}$ в реакционной ванне, соответствует стехиометрии между суммой металлов и халькогеном, а при 0.08 моль/л в слое присутствует избыток серы (50.75 ат\%). При максимальной концентрации соли кадмия в реакторе в синтезированном слое вновь образуется избыток металлов. Исходя из данных EDX анализа формульный состав синтезированных в работе слоев в зависимости от содержания соли кадмия в реакционной ванне можно записать следующим образом:

$\mathrm{Cd}_{0.182} \mathrm{~Pb}_{0.821} \mathrm{~S}_{0.997}(0.01$ моль/л),

$\mathrm{Cd}_{0.26} \mathrm{~Pb}_{0.74} \mathrm{~S}_{0.998}(0.02$ моль/л),

$\mathrm{Cd}_{0.297} \mathrm{~Pb}_{0.703} \mathrm{~S}$ (0.04 моль/л),

$\mathrm{Cd}_{0.092} \mathrm{~Pb}_{0.908} \mathrm{~S}$ (0.8 моль/л),

$\mathrm{Cd}_{0.424} \mathrm{~Pb}_{0.580} \mathrm{~S}_{0.996}(0.1$ моль/л).

Таким образом, все пленки, за исключением пленочного слоя, полученного при 0.08 моль/л ацетата кадмия в реакционной смеси, содержат помимо твердого раствора аморфную фазу CdS.

Таким образом, в процессе химического осаждения при варьировании содержания ацетата кадмия от 0.01 до 0.1 моль/л в реакционной ванне были получены поликристаллические пленки пересыщенных твердых растворов замещения $\mathrm{Cd}_{x} \mathrm{~Pb}_{1-x} \mathrm{~S}$ с кубической структурой $B 1$ (пр. гр. $F m \overline{3} m)$. Обсуждаемые тонкопленочные соединения содержат твердый раствор либо одновременно с ним аморфную фазу сульфида кадмия.

Согласно электронно-микроскопическим и рентгеновским исследованиям, наблюдается немонотонная эволюция морфологии поверхности и структурного состояния обсуждаемых пленок от концентрации $\mathrm{Cd}\left(\mathrm{CH}_{3} \mathrm{COO}\right)_{2}$ в реакторе, что обусловливает возможное разнообразие функциональных свойств.

\section{3. Фоточувствительные и сенсорные свойства}

Преимущество синтезированных соединений $\mathrm{Cd}_{x} \mathrm{~Pb}_{1-x} \mathrm{~S}$ состоит в возможности широкого варьирования их функциональных свойств в зависимости от состава, морфологии, кристаллического строения, уровня пересыщения твердого раствора по кадмию и типа проводимости, что позволяет „настроить“ полупроводниковые слои на возникновение фотоэффекта при облучении либо специфической химической активности к токсичным газам.

Изменение состава и морфологии исследуемых пленок отразилось, как видно из рис. 5, на их фотоэлектрических свойствах, в частности на вольтовой чувствительности $U_{s}(1)$ при инфракрасном облучении и темновом сопротивлении $R_{d}(2)$. Наблюдается рост вольтовой фоточувствительности пленок твердых растворов $\mathrm{Cd}_{x} \mathrm{~Pb}_{1-x} \mathrm{~S}$, осажденных из реакционных ванн,

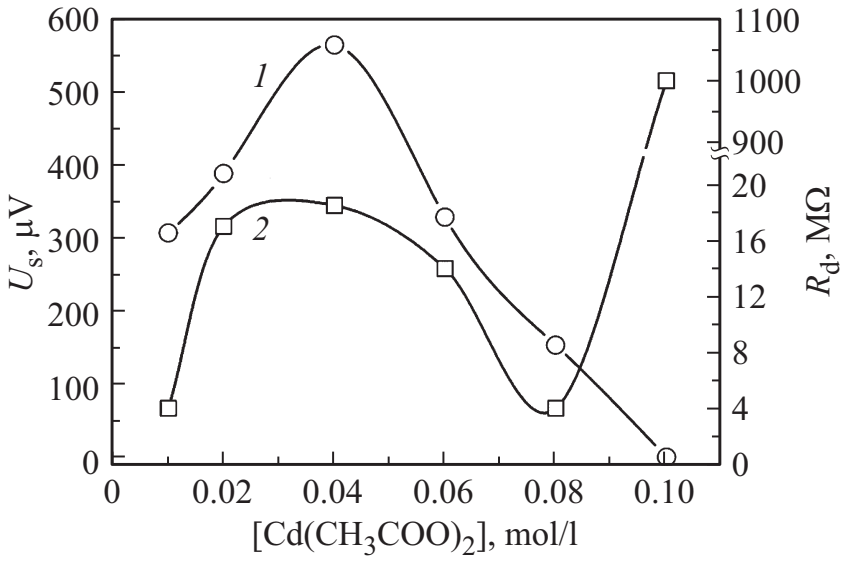

Рис. 5. Зависимость вольтовой чувствительности $U_{s}(1) \quad$ и темнового сопротивления $R_{d} \quad(2)$ пленок твердых растворов $\mathrm{Cd}_{x} \mathrm{~Pb}_{1-x} \mathrm{~S}$ от содержания $\mathrm{Cd}\left(\mathrm{CH}_{3} \mathrm{COO}\right)_{2}$ в реакционной ванне.

содержащих от 0.01 до 0.04 моль/л $\mathrm{Cd}\left(\mathrm{CH}_{3} \mathrm{COO}\right)_{2}$, в $\sim 2$ раза. Дальнейшее повышение концентрации ацетата кадмия до 0.08 моль/л в реакторе приводит к резкому падению вольтовой чувствительности изучаемых слоев, а затем к ее фактическому отсутствию у пленки, полученной при максимальном содержании соли кадмия (0.1 моль/л).

Что касается темнового сопротивления $R_{d}$, зависимость его от содержания ацетата кадмия в реакционной ванне имеет более сложный характер: вначале наблюдается монотонный рост от $\sim 70$ до $\sim 350 \mathrm{MOM} \mathrm{на}$ квадрат, а затем его снижение до $\sim 70$ МОм. Дальнейшее резкое повышение $R_{d}$ до 1000 МОм на квадрат у пленки, формульный состав которой $\mathrm{Cd}_{0.424} \mathrm{~Pb}_{0.580} \mathrm{~S}_{0.996}$, связано со значительным содержанием в ней аморфной фазы сульфида кадмия помимо твердого раствора $\mathrm{Cd}_{0.09} \mathrm{~Pb}_{0.91} \mathrm{~S}$.

Сопоставление измеренных фотоэлектрических характеристик $\left(U_{s}\right.$ и $\left.R_{d}\right)$ с результатами рентгеноструктурного и элементного анализов позволяет высказать предположение о том, что существует некоторое критическое количество аморфной фазы $\mathrm{CdS}$ в составе полупроводникового слоя, стимулирующее усиление его фоточувствительных свойств. Так, пленка с формульным составом $\mathrm{Cd}_{0.297} \mathrm{~Pb}_{0.703} \mathrm{~S}$ (0.04 моль/л), имеющая максимальную вольтовую чувствительность, состоит из твердого раствора $\mathrm{Cd}_{0.053} \mathrm{~Pb}_{0.947} \mathrm{~S}$ и, возможно, оптимального для этих условий содержания аморфного $\mathrm{CdS}$. Пленка, представляющая только твердый раствор $\mathrm{Cd}_{0.086} \mathrm{~Pb}_{0.914} \mathrm{~S}$, полученная при 0.08 моль/л ацетата кадмия в реакционной ванне, отвечает средним значениям выявленной величины сигнала $U_{s}$.

Вольт-амперные характеристики $(a)$ и плотность тока $(b)$ обсуждаемых слоев $\mathrm{Cd}_{x} \mathrm{~Pb}_{1-x} \mathrm{~S}$, полученные при их освещении пучком света от симулятора солнечного излучения и различных концентрациях ацетата кадмия в реакционной ванне, приведены на рис. 6. В диапазоне 

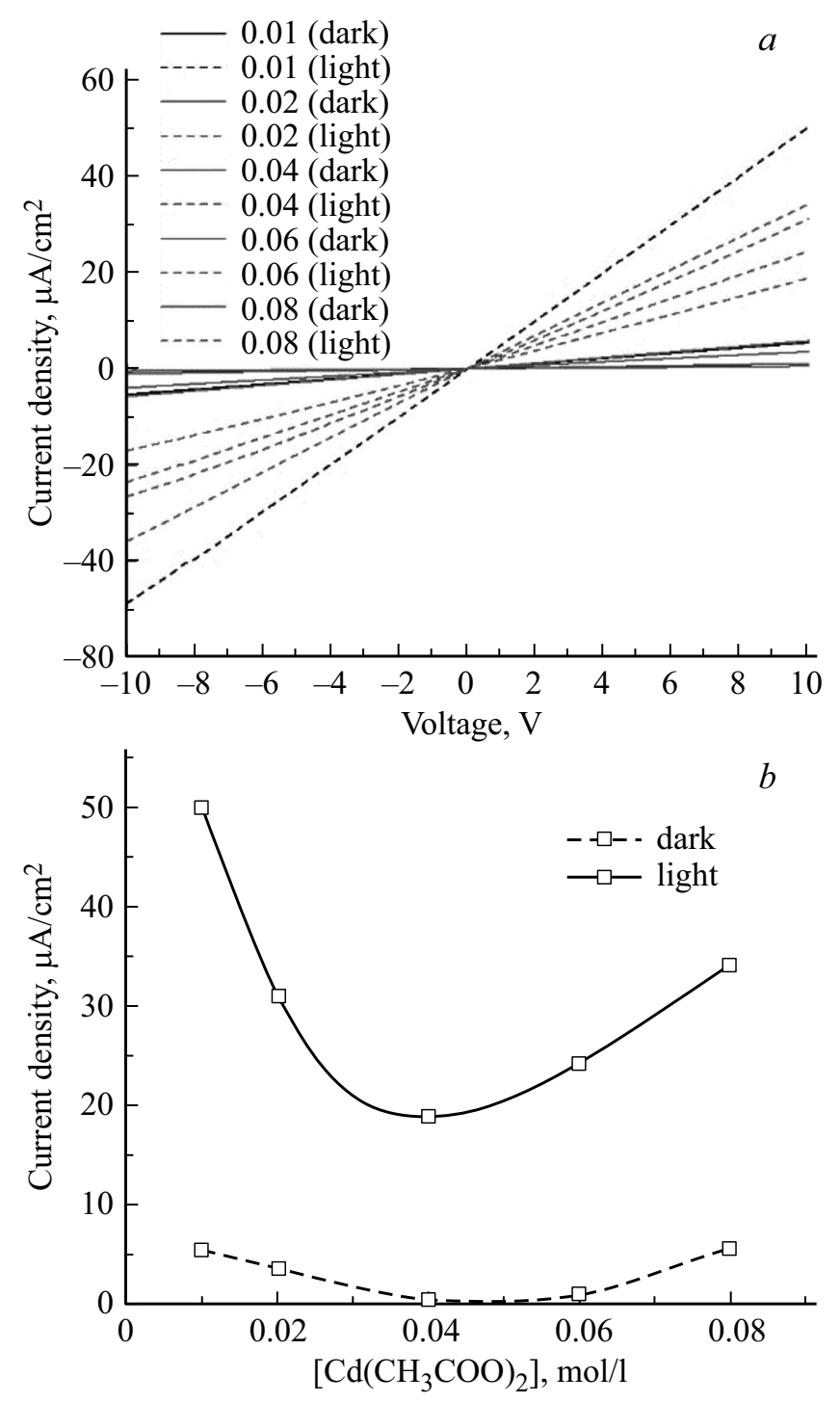

Рис. 6. Вольт-амперные характеристики $(a)$ и зависимость плотности тока $(b)$ от концентрации ацетата кадмия в реакционной ванне.

значений приложенного напряжения от -10 до $10 \mathrm{~B}$ вольт-амперные характеристики являются симметричными и линейными. Плотности светового и темнового токов как функции концентрации соли кадмия в реакционной ванне имеют асимбатные зависимости вольтой чувствительности $U_{s}=f\left[\mathrm{Cd}\left(\mathrm{CH}_{3} \mathrm{COO}\right)_{2}\right]$ с минимумом в точке, соответствующей 0.04 моль/л $\mathrm{Cd}\left(\mathrm{CH}_{3} \mathrm{COO}\right)_{2}$, где наблюдается разрушение кристаллитов с образованием зерен с неровными краями. Как уже отмечалось нами в работе [25], тонкопленочные соединения с четкой кристаллографической огранкой кристаллитов обладают максимальным фототоком, им отвечают слои, полученные при 0.01 и 0.08 моль/л ацетата кадмия в реакторе.

Еще одной возможной областью применения синтезированных в работе тонких пленок на основе сульфидов свинца и кадмия является использование их для создания тонкопленочных химических сенсоров, в частности для решения задач по определению в воздушной среде некоторых токсичных газов.

В [26] нами было показано, что тонкие пленки твердого раствора $\mathrm{Cd}_{x} \mathrm{~Pb}_{1-x} \mathrm{~S}$ имеют достаточно низкий порог обнаружения в воздухе диоксида азота $\mathrm{NO}_{2}$. Особенно наглядно это проявляется при использовании в реакционной ванне ацетата кадмия при химическом осаждении твердых растворов [8]. Однако влияние концентрации ацетата кадмия на поверхностно-чувствительные свойства сенсорных элементов на основе $\mathrm{Cd}_{x} \mathrm{~Pb}_{1-x} \mathrm{~S}$ ранее не изучалось. Принцип действия химических сенсоров основывается на изменении их электрофизических характеристик при адсорбции диоксида азота. В частности, после контакта с газом происходит изменение (понижение или повышение) омического сопротивления $R_{\tau}$ пленки по сравнению с его исходным значением $R_{0}$. В работе были изготовлены сенсорные элементы размером $5 \times 5$ мм из слоев $\mathrm{Cd}_{x} \mathrm{~Pb}_{1-x} \mathrm{~S}$, полученных при вариации концентрации ацетата кадмия в реакционной смеси. Газочувствительность сенсоров оценивалась по изменению соотношения $R_{0} / R_{\tau}$ после контакта с газом. Предварительно установленный тип проводимости синтезированных в работе пленок, как выяснилось, оказывает определяющее влияние на характер изменения омического сопротивления. Так, слои бинарного $\mathrm{PbS}$ и твердых растворов $\mathrm{Cd}_{x} \mathrm{~Pb}_{1-x} \mathrm{~S}$ с относительно низким содержанием кадмия $(0 \leq x \leq 0.033)$ являются полупроводниками $n$-типа, в то время как пленки твердых растворов с более высоким содержанием кадмия $(0.053 \leq x \leq 0.09)$ полупроводниками $p$-типа. В результате при контакте с $\mathrm{NO}_{2}$ был зарегистрирован взаимно противоположный характер изменения омического сопротивления пленок: понижение $R_{\tau}$ в первом случае и повышение во втором.

Концентрационные и кинетические зависимости отклика сенсорных элементов, приведенные на рис. 7, свидетельствуют о корреляции между содержанием в газовой фазе определяемого газа и уменьшением или увеличением омического сопротивления изготовленных пленочных элементов. Сенсорный элемент, выполненный на основе индивидуального сульфида свинца (1), являющегося базовым соединением при формировании твердых растворов $\mathrm{Cd}_{x} \mathrm{~Pb}_{1-x} \mathrm{~S}$, практически не проявляет газочувствительных свойств до концентрации диоксида азота, равной $20 \mathrm{мг} / \mathrm{m}^{3}$. Далее наблюдается резкое увеличение отношения $R_{0} / R_{\tau}$ в $\sim 1.5$ раза при $200 \mathrm{Mr} / \mathrm{M}^{3}$ (рис. 7,a). При контакте сенсорного элемента на основе пленки твердого раствора $\mathrm{Cd}_{0.021} \mathrm{~Pb}_{0.979} \mathrm{~S}(2)$ с $\mathrm{NO}_{2}$ относительное изменение сопротивления начинает возрастать уже с концентрации его в воздушной среде $0.1 \mathrm{Mг} / \mathrm{M}^{3}$, превышая исходное значение $R_{0} / R_{\tau}$ в $\sim 2.4$ раза. Параллельно, но с меньшей скоростью, наблюдается повышение $R_{0} / R_{\tau}$ после контакта пленки $\mathrm{Cd}_{0.033} \mathrm{~Pb}_{0.967} \mathrm{~S}(3)$ с диоксидом азота, a пленка $\mathrm{Cd}_{0.086} \mathrm{~Pb}_{0.914} \mathrm{~S}(4)$ фактически не проявляет газочувствительных свойств. При использовании сенсорных элементов на основе пленок твердых растворов $\mathrm{Cd}_{0.086} \mathrm{~Pb}_{0.914} \mathrm{~S}(5)$ и $\mathrm{Cd}_{0.09} \mathrm{~Pb}_{0.91} \mathrm{~S}(6)$ наблюдается снижение $R_{0} / R_{\tau}$ на 20 и $40 \%$ соответственно. 

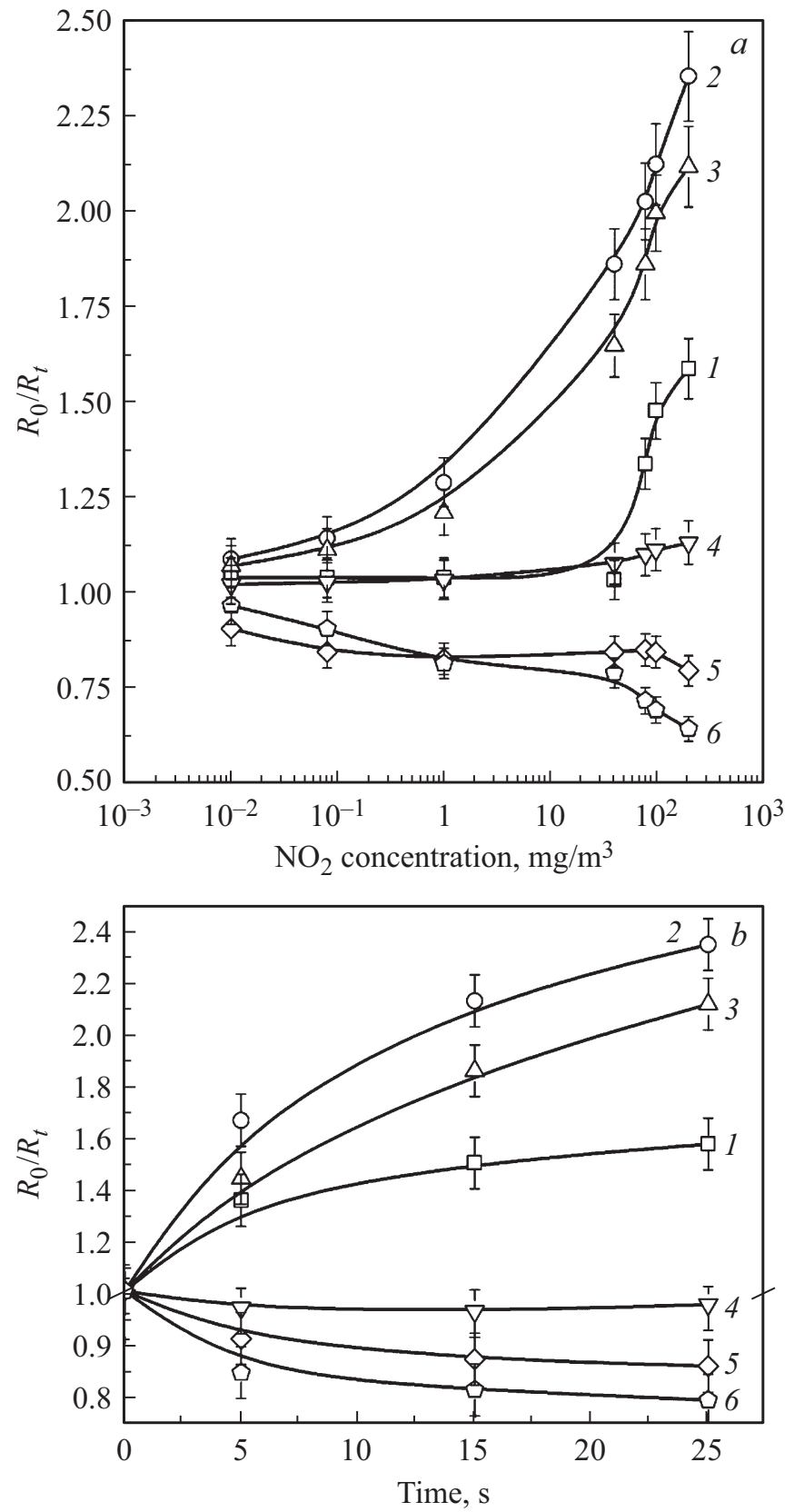

Рис. 7. Концентрационные $(a)$ и кинетические $(b)$ зависимости изменения отношения омического сопротивления $R_{0} / R_{\tau}$ пленок, полученных из реакционной смеси, содержащей. $\mathrm{Cd}\left(\mathrm{CH}_{3} \mathrm{COO}\right)_{2}$, моль/л: 0 (1), 0.01 (2), 0.02 (3), 0.04 (4), 0.08 (5), 0.1 (6). Продолжительность контакта сенсорных элементов с диоксидом азота составила $25 \mathrm{c}(a)$, а концентрация $\mathrm{NO}_{2}-200 \mathrm{M} \Gamma / \mathrm{M}^{3}(b)$.

Анализ, представленных на рис. $7, b$ кинетических зависимостей, показывает достаточно высокую скорость адсорбционного взаимодействия сенсорных элементов с газом: уже в первые 5 с контакта с $\mathrm{NO}_{2}$ достигается изменение относительного сопротивления $R_{0} / R_{\tau}$ на $15-60 \%$ в зависимости от содержания $x \mathrm{~B}^{-} \mathrm{Cd}_{x} \mathrm{~Pb}_{1-x} \mathrm{~S}$. Причем увеличение продолжительности контакта плен- ки с газом не приводит к изменению характера зависимостей, а только сопровождается ростом абсолютных величин сенсорного отклика, достигая насыщения для пленок, полученных в присутствии 0.04 (4), 0.08 (5) и $0.1(6)$ моль/л соли $\mathrm{Cd}\left(\mathrm{CH}_{3} \mathrm{COO}\right)_{2}$ в реакционной ванне к 15-й секунде контакта с газом. Сенсорные элементы, изготовленные на основе пленок, синтезированных при минимальных концентрациях соли кадмия (0.01 и 0.02 моль/л) в реакторе, обеспечивают рост $R_{0} / R_{\tau}$ на 110-130\% при 25-секундном контакте с $\mathrm{NO}_{2}$ по сравнению с исходным состоянием.

Омическое сопротивление сенсорных элементов после извлечения из измерительной ячейки с $\mathrm{NO}_{2}$ и помещения в атмосферу чистого воздуха возвращается к своему исходному значению $R_{0}$ при комнатной температуре в течение от нескольких минут до 2-3 ч, что указывает на физический характер взаимодействия тонкопленочных слоев $\mathrm{Cd}_{x} \mathrm{~Pb}_{1-x} \mathrm{~S}$ с диоксидом азота.

\section{4. Заключение}

Химическим осаждением из аммиачно-цитратной реакционной ванны получены поликристаллические пленки $\mathrm{CdPbS}$ толщиной от 0.5 до $\sim 1.0$ мкм. Электронномикроскопическими исследованиями показана нелинейная эволюция микроструктуры тонкопленочных слоев на подложках из ситалла при варьировании содержания ацетата кадмия в реакционной ванне от 0.01 до 0.1 моль/л.

Рентгеновской дифракцией в интервале концентраций от 0.01 до 0.1 моль/л ацетата кадмия в реакторе установлено образование пересыщенных твердых растворов $\mathrm{Cd}_{x} \mathrm{~Pb}_{1-x} \mathrm{~S}(x \leq 0.09)$ с кубической гранецентрированной решеткой типа $\mathrm{NaCl}(B 1$, пр.гр. $F m \overline{3} m)$. С использованием полнопрофильного анализа рентгенограмм с компьютерным моделированием в программе FullProf и „модифицированного“ уравнения Уильямсона-Холла проведена комплексная оценка размеров кристаллитов, формирующих пленку, степени их текстурированности и величины микронапряжений пленок твердых растворов $\mathrm{Cd}_{x} \mathrm{~Pb}_{1-x} \mathrm{~S}$, осажденных на ситалловые подложки.

Установлен характер изменения вольтовой чувствительности, фототока и сенсорного отклика пленок твердых растворов $\mathrm{Cd}_{x} \mathrm{~Pb}_{1-x} \mathrm{~S}$ к присутствию в воздухе диоксида азота в зависимости от структурно-морфологических особенностей и условий их формирования.

\section{Финансирование работы}

Работа выполнена при финансовой поддержке Министерства науки и высшего образования Российской Федерации, проект № FEUZ-2020-0058 (Н687.42Б.223/20), гранта РФФИ 20-48-660041p_а и в рамках государственного задания Министерства образования и науки (тема „Поток“ № AAAA-A18-118020190112-8).

\section{Конфликт интересов}

Авторы заявляют, что у них нет конфликта интересов. 


\section{Список литературы}

[1] W.W. Scanlon. J. Phys. Chem. Solids, 8, 423 (1959).

[2] P.M. Khanzode, D.I. Halge, V.N. Narwade, J.W. Dadge, K.A. Bogle. Optik, 226 (1), 165933 (2020).

[3] E. Pentia, V. Draghici, G. Sarau. J. Electrochem. Soc., 151 (11), G729 (2004).

[4] A. Ounissi, N. Ouddai, S. Achour. Eur. Phys. J. Appl. Phys., 37 (3), 241 (2007).

[5] V. Rakovics. Mat. Res. Soc. Symp. Proc., 900, 87 (2005).

[6] A.E. Rakhshani, B. Pradeep, H.A. Ramazaniyan. Chem. Sol. Deposit. of Semicond. and Non-Metal. Films: Proc. Int. Symp. Electrochem. Soc., 32, 49 (2006).

[7] P.L. Nichols, Z. Liu, L. Yin, S. Turkdogan, F. Fan, C.Z. Ning. Nano Lett., 15, 909 (2015).

[8] A.E. Bezdetnova, V.F. Markov, L.N. Maskaeva, Yu.G. Shashmurin, A.S. Frants, T.V. Vinogradova. J. Anal. Chem., 74 (12), 1256 (2019).

[9] D.A. Caselli, C.Z. Ning. Opt. Express, 19 (S4), A686 (2011).

[10] G.L. Tan, L. Liu, W. Wu. AIP Adv., 4, 067107 (2014).

[11] K.E. Suryavanshi, R.B. Dhake, A.M. Patil, M.R. Sonawane. Optik, 218, 165008 (2020).

[12] R.K. Dutta. Nat. Sci., 9 (1), 21 (2020).

[13] L.N. Maskaeva, E.V. Mostovshchikova, I.V. Vaganova, V.F. Markov, V.I. Voronin, A.D. Kutyavina, E.G. Vovkotrub. Thin Sol. Films, 718, 138468 (2020).

[14] В.Ф. Марков, Л.Н. Маскаева, П.Н. Иванов. Гидрохимическое осаждение пленок сульфидов металлов: моделирование, эксперимент (Екатеринбург, УрО РАН, 2006).

[15] S. Rajathi, K. Kirubavathi, K. Selvaraju. J. Taibah Univ. for Sci., 11 (6), 1296 (2017).

[16] S.R. Deo, A.K. Singh, L. Deshmukh, L.J. Paliwal, R.S. Singh. Optik, 126 (20), 2311 (2015).

[17] M.A. Barote, S.S. Kamble, L.P. Deshmukh, E.U. Masumdar. Ceram. Int., 39 (2), 1463 (2013).

[18] S.M. Ho. Int. J. Thin. Films Sci. Techn., 10 (1), 45 (2021).

[19] A. Mohammed, Ali M. Mousa, J.P. Ponpon. J. Semicond. Technol. Sci., 9 (2), 117 (2009).

[20] H.M. Rietveld. J. Appl. Crystallogr., 2 (2), 65 (1969).

[21] D.L. Bush, J.E. Post. Rev. in Min., 20, 369 (1990).

[22] J. Rodriges-Carvajal. Physica B, 192 (1-2), 55 (1993).

[23] G.K. Williamson, W.H. Hall. Acta Metall., 1 (1), 22 (1953).

[24] Л.Е. Шелимова, В.Н. Томашик, В.И. Грыцив. Диаграммы состояния в полупроводниковом материаловедении (системы на основе халькогенидов $\mathrm{Si}, \mathrm{Ge}, \mathrm{Sn}, \mathrm{Pb}$ ) (M., Наука, 1991) гл. 9 с. 256.

[25] Л.Н. Маскаева, Е.В. Мостовщикова, В.Ф. Марков, В.И. Воронин, А.В. Поздин, И.О. Селянин, А.И. Михайлова. ФТП, 55 (11), 1049 (2021).

[26] В.Ф. Марков, Л.Н. Маскаева, Ю.С. Поликарпова, М.П. Миронов, В.Н. Родин, Л.С. Соловьев, Б.В. Берг, В.Н. Потапов. Патент РФ 2305830. Заявка 2006115277/28 от 03.05.2006, опубл. 10.09.2007.

Редактор Г.А. Оганесян

\section{Structure and morphology effects on sensing properties $\mathbf{C d} x \mathbf{P b}_{1-x} \mathbf{S}$ films}

\author{
L.N. Maskaeva ${ }^{1,2}$ I.V. Vaganova ${ }^{1,2}$ V.F. Markov ${ }^{1,2}$, \\ A.E. Bezdetnova ${ }^{1}$, A.D. Selyanina ${ }^{1}$, \\ V.I. Voronin ${ }^{3}$, I.O. Selyanin ${ }^{1,4}$ \\ ${ }^{1}$ Ural Federal University \\ named after the first President of Russia B.N. Yeltsin, \\ 620002 Yekaterinburg, Russia \\ ${ }^{2}$ Ural State Fire Service Institute \\ of Emergency Ministry of Russia, \\ 620062 Yekaterinburg, Russia \\ ${ }^{3}$ Miheev Institute of Metal Physics \\ of Ural Branch of Russian Academy of Sciences, \\ 620108 Yekaterinburg, Russia \\ ${ }^{4}$ Institute of solid state chemistry \\ of Ural Branch of Russian Academy of Sciences, \\ 620990 Yekaterinburg, Russia
}

\begin{abstract}
Polycrystalline films of $\mathrm{Cd}_{x} \mathrm{~Pb}_{1-x} \mathrm{~S}$ $(0.021 \leq x \leq 0.090)$ supersaturated substitutional solid solutions with a cubic structure $B 1(F m \overline{3} m$ space group) have been obtained with varying cadmium acetate salt $\mathrm{Cd}\left(\mathrm{CH}_{3} \mathrm{COO}\right)_{2}$ in the reaction mixture within $0.01-0.1 \mathrm{~mol} / 1$ on the sitall substrates. Their thickness changed from $\sim 0.4$ to $\sim 1.0$ microns. A correlation has been established between the structural-morphological and functional properties of $\mathrm{Cd}_{x} \mathrm{~Pb}_{1-x} \mathrm{~S}$ thin-film layers. The extreme character of the voltage sensitivity dependence on the cadmium salt concentration in the reaction bath is associated with the nonmonotonic introduction of cadmium into the $\mathrm{PbS}$ crystal lattice. It is shown that the maximum photocurrent is possessed by $\mathrm{Cd}_{x} \mathrm{~Pb}_{1-x} \mathrm{~S}$ thin-film layers formed from crystallites with pronounced faceting. We have found the surface sensitivity of the $\mathrm{Cd}_{x} \mathrm{~Pb}_{1-x} \mathrm{~S}$ films to the presence of $\sim 0.02 \mathrm{mg} / \mathrm{m}^{3} \mathrm{NO}_{2}$ in the air, which is significantly lower than the maximum allowable concentration.
\end{abstract}

